Supporting Information for

\title{
Effect of Surface Orientation on Methanol Adsorption and Thermally Induced Structural Transformations on Copper Surfaces
}

\author{
Roey Ben David, ${ }^{\dagger}$, Adva Ben Yaacov, ${ }^{\dagger}$, Baran Eren, $,{ }^{*}, \dagger$ \\ $\dagger$ Department of Chemical and Biological Physics, Weizmann Institute of Science, 234 Herzl Street, \\ 76100 Rehovot, Israel, \\ *E-mail: baran.eren@weizmann.ac.il_ Phone: +972 8-934-3708
}

\section{Section S1 - Low Energy Electron Diffraction (LEED)}

Fig. S1 shows the LEED patterns obtained from the clean Cu surfaces (Fig. S1a-c), after 0.55 L methanol dosage at $90 \mathrm{~K}$ (Fig. S1d-f), and after subsequent heating of the surfaces to $120 \mathrm{~K}$ (Fig. S1g-i). Diffraction patterns were obtained with a BDL800IR LEED/AES spectrometer (OCI Vacuum Microengineering) at an electron energy of 90-100 eV, and captured by a 12-bit CCD camera. Before methanol exposure (Fig. S1a-c) only the diffraction spots of bare metals were obtained, with 3-fold, 4-fold and 2-fold rotational symmetries of $\mathrm{Cu}(111), \mathrm{Cu}(100)$ and $\mathrm{Cu}(110)$, respectively. After $0.55 \mathrm{~L}$ methanol exposure at $90 \mathrm{~K}$ (Fig. S1d-f), additional diffraction spots, ascribed to ordered methanol adlayer, were observed on $\mathrm{Cu}(111)$ (Fig. S1d and j). In contrast, no indication of an ordered methanol structure is found in the LEED patterns of $\mathrm{Cu}(100)$ and $\mathrm{Cu}(110)$ at $90 \mathrm{~K}$ (Fig. S1e-f). The obtained diffraction patterns for $\mathrm{Cu}(111)$ can be attributed to two methanol adlayer structures: a $(2 \times 2)$ structure or three equivalent domains of a $(1 \times 2)$ adlayer structure rotated by $120^{\circ}$ with respect to one another. These two possibilities are discussed in the main text and correlated with the proposed H-bonded structures of methanol. After heating to $120 \mathrm{~K}$ (Fig. S1gi), the LEED patterns associated with the methanol adlayer on $\mathrm{Cu}(111)$ vanished (Fig. S1g). Recalling that $120 \mathrm{~K}$ is below the desorption temperature in $\operatorname{UHV}(\sim 140 \mathrm{~K})$, the disappearance of the methanol-related diffraction spots indicates disordering in the adsorbed layer, rather than desorption. For $\mathrm{Cu}(100)$ and $\mathrm{Cu}(110)$ the diffractograms remained unchanged following heating to $120 \mathrm{~K}$. 
$\mathrm{Cu}(111)$
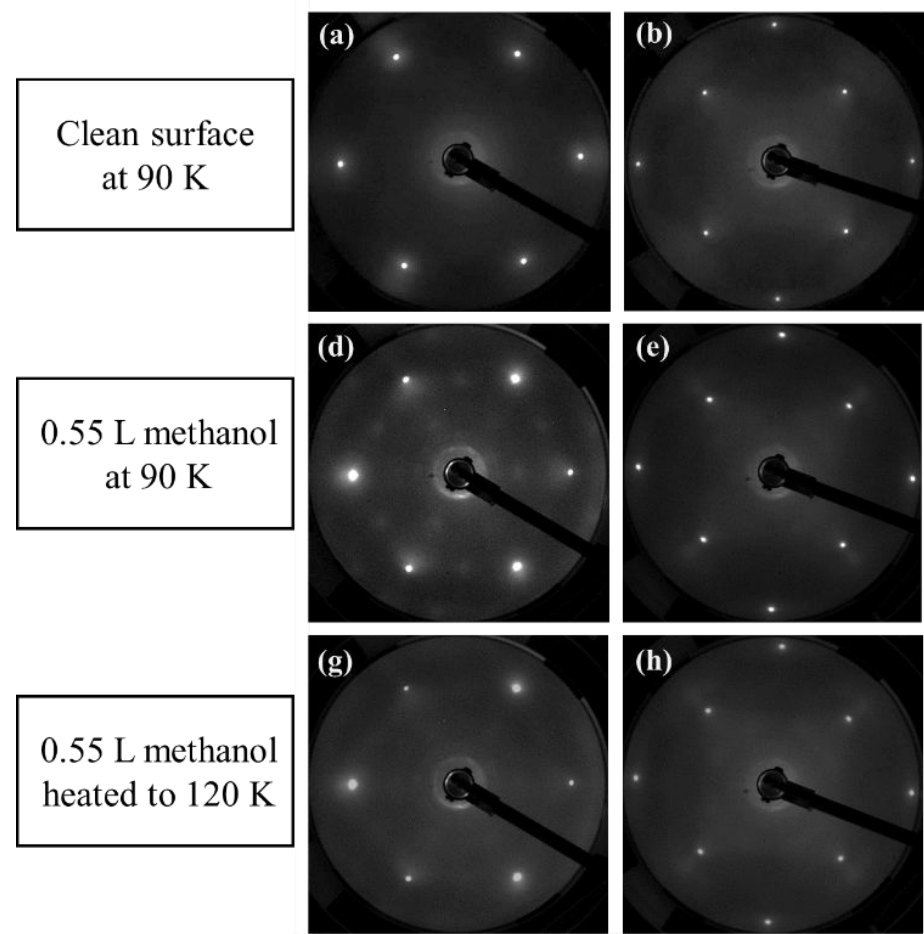

$0.55 \mathrm{~L}$ methanol heated to $120 \mathrm{~K}$

$\mathrm{Cu}(100)$

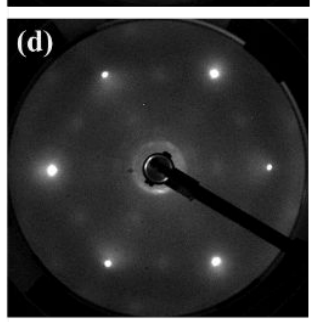

$\mathrm{Cu}(110)$
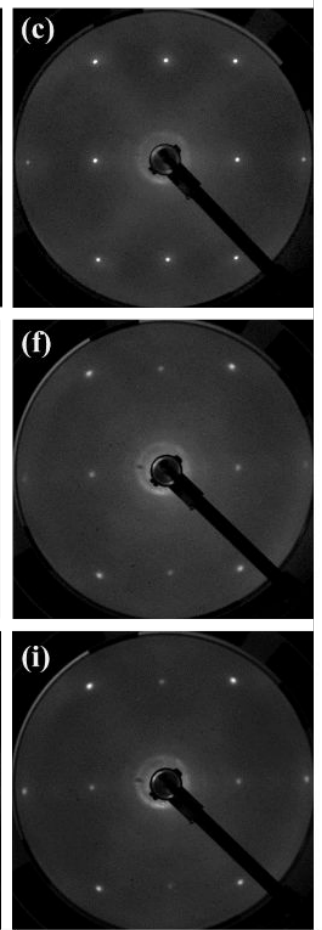

(j)

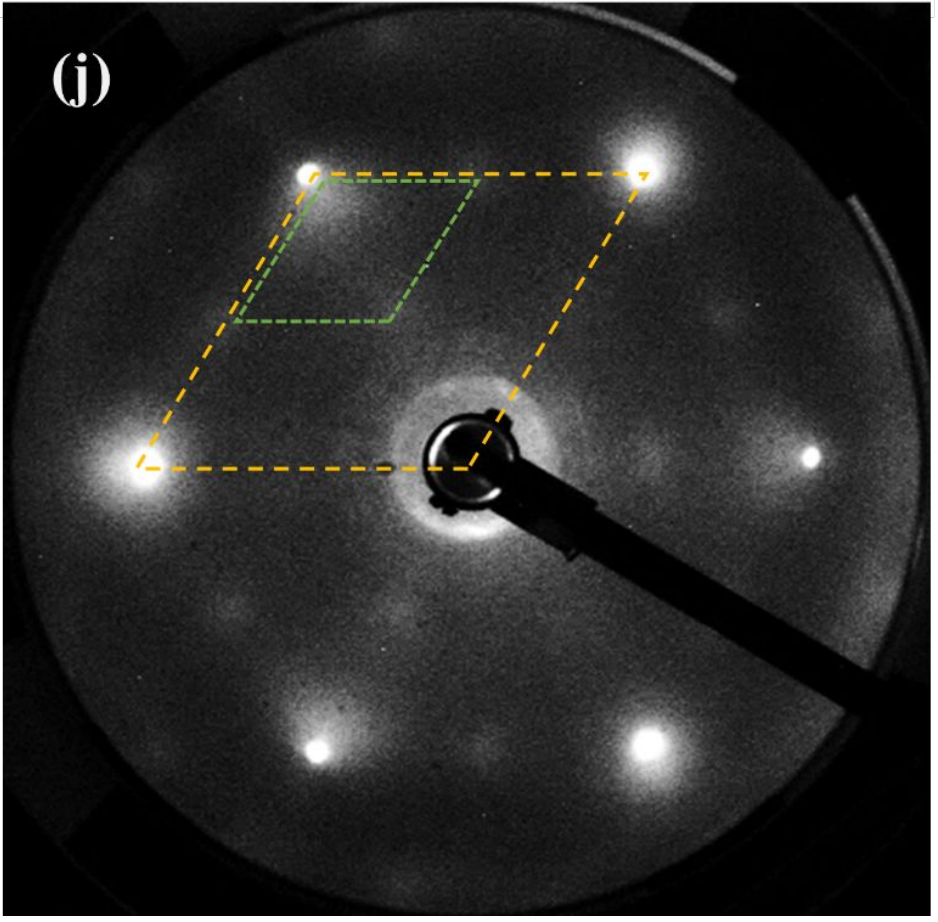

Fig. S1. LEED patterns (at 90-100 eV) of $\mathrm{Cu}(111), \mathrm{Cu}(100)$ and $\mathrm{Cu}(110)$. (a)-(c): Clean surfaces at $90 \mathrm{~K}$ in UHV, (d)-(f): following $0.55 \mathrm{~L}$ methanol exposure at $90 \mathrm{~K}$ and (g)-(i): After heating the pre-covered surfaces to $120 \mathrm{~K}$. (j) is an enlarged image of (d) combined with the reciprocal lattice units cells of $\mathrm{Cu}(111)$ surface atoms (orange dashed line) and methanol adlayer (green dashed line). 


\section{Section S2 - PM-IRRAS of the C-O stretching band}

Fig. S2 is a zoom-in of the C-O stretching region (980-1100 cm-1) of Fig. 5 of the main text, shown only for temperatures of $90 \mathrm{~K}$ and $130 \mathrm{~K}$. At a surface temperature of $90 \mathrm{~K}$ (after dosing $0.55 \mathrm{~L}$ methanol), nearly identical C-O stretching band positioned at $1045 \mathrm{~cm}^{-1}$ is obtained for the three surfaces. Heating the surface to $130 \mathrm{~K}$ results in red-shifting of the peak to $1038 \mathrm{~cm}^{-1}$ for $\mathrm{Cu}(111)$ and splitting into a multipeak profile, with peak positions at $\sim 1028,1036,1045 \mathrm{~cm}^{-1}$, for $\mathrm{Cu}(100)$ and $\mathrm{Cu}(110)$. The interpretation of those temperature-induced spectral changes and the suggested peaks assignment are discussed in the main text.

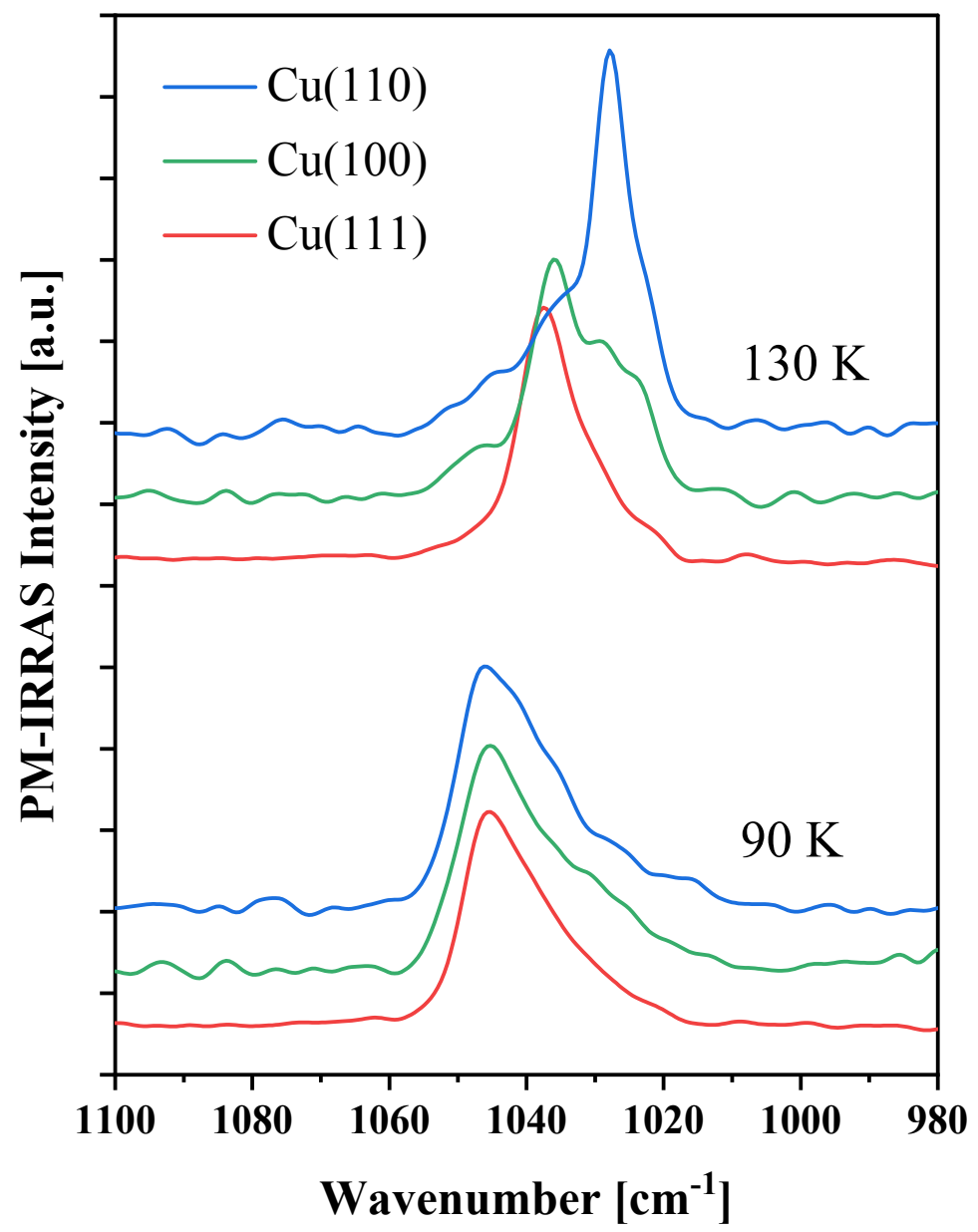

Fig. S2. C-O stretching region in the PM-IRRAS spectra of methanol (after 0.55 L dosage) on $\mathrm{Cu}(111)$, $\mathrm{Cu}(100)$ and $\mathrm{Cu}(110)$ surfaces at $90 \mathrm{~K}$ and $130 \mathrm{~K}$ (the full spectra are given in Fig. 5). 